\title{
WOMEN'S KNOWLEDGE AND BELIEFS TOWARDS VACCINATION FOR INFLUENZA DURING PREGNANCY IN TURKEY AND UNDERLYING FACTORS OF MISINFORMATION: A SINGLE-CENTRE CROSS-SECTIONAL STUDY
}

\author{
Çiğdem Pulatoğlu', Gökçe Turan² \\ 'Department of Obstetrics and Gynaecology, Istinye University Hospital Gaziosmanpaşa Medical Park, Istanbul, Turkey \\ 2Department of Obstetrics and Gynaecology, Kirikhan State Hospital, Hatay, Turkey
}

\section{SUMMARY}

Objective: The aim of the study was to evaluate the knowledge and perceptions of the pregnant women presenting to our hospital for seasonal vaccination for influenza and to determine the factors associated with it.

Method: In this cross-sectional study pregnant woman presenting to our hospital between October 2018 and March 2019 were evaluated. A non-validated, well-detailed questionnaire addressing the vaccination rates, participants' perceptions about the facts behind the vaccination for influenza and the factors associated with refusal of vaccination was performed. Women's knowledge level provided by their healthcare providers was also questioned.

Results: A total of 250 participants were included in the study. The average age of the patients was $28.85 \pm 5.42$ years (range 18-43); and the average pregnancy week was $19 \pm 9.75$. It was determined that $98 \%(n=245)$ of the participants did not have any vaccinations before, and $98.8 \%(n=247)$ did not have any vaccination during their current pregnancy. $65.2 \%(n=163)$ of the participants did not know that the vaccination for influenza was safe in pregnancy; and $64 \%(n=160)$ did not know that the vaccination for influenza was recommended in pregnancy. The most frequent responses given by the participants to justify their refusal for the vaccination was "my doctor was against" and "it can be harmful to my baby" $(25.6 \%$ and $24 \%$, respectively). It was determined that $98.4 \%(n=246)$ of the participants were not recommended about the vaccination for influenza by any healthcare centres; and $92.8 \%(n=232)$ did not receive any information on vaccination for influenza.

Conclusion: The knowledge of the participants on vaccination for influenza was inadequate and had misconceptions. The inadequacy of healthcare employees, government institutions and the media may have played roles in this outcome. The reasons underlying the inadequacy of the healthcare providers on vaccination for influenza may be questioned.

Key words: seasonal influenza, vaccination, influenza, pregnancy, maternal immunization

Address for correspondence: Ç. Pulatoğlu, Department of Obstetrics and Gynaecology, Istinye University Hospital Gaziosmanpaşa Medical Park, Merkez mahallesi Hanımefendi Sokak 105/5 Şişli, Istanbul, Turkey. E-mail: cigdempulatoglu@gmail.com

https://doi.org/10.21101/cejph.a5907

\section{INTRODUCTION}

It is estimated that an average of $291,243-645,832$ seasonal influenza-related deaths (4.0-8.8 per 100,000 people) occur each year worldwide (between 0.1 and 6.4 per 100,000 people under the age of 65 ; between 2.9 and 44.0 per 100,000 patients between the ages of 64 and 74; and between 17.9 and 223.5 per 100,000 for patients above the age of 75) (1). Identifying risk groups for severe influenza disease is essential in the efforts for prevention and control. Seasonal influenza increases the hospitalization risk during pregnancy and in infants who are under six months of age (2). Seasonal influenza vaccination is an effective method in preventing influenza infections and epidemics (3).

The World Health Organization (WHO) defined the priority groups again in 2012 and determined pregnant women as the priority target group recommending influenza vaccination during pregnancy to reduce the serious infection risk during pregnancy (4). In Turkey, too, vaccination for influenza is recommended by the Ministry of Health for people who are at and above the age of 65 , to chronic patients who are in the risk group, and to people who stay in nursing homes. The Ministry covers the costs of the vaccinations. Since November 2016 pregnant women who were in the 2nd and 3rd trimester have also been included in this list (5).

Dodds et al. conducted a study and reported that pregnant women who had seasonal influenza infection were in a higher complication risk compared to non-pregnant women (6). Tamma et al. conducted a study and reported that the reason why seasonal influenza was more dangerous in pregnant women than in nonpregnant was the prolonged hospitalization durations due to respiratory distress, increased risk of preterm labour and de- 
livery, pneumonia, adult respiratory distress syndrome (ARDS), increased risk of severe sepsis, and death (7). In addition, vaccination against influenza during pregnancy has proved its efficiency not only in mothers but also in newborns with the help of passive transplacental antibody transfer (8).

Several studies showed that influenza vaccination is safe in pregnancy, and vaccination does not cause negative outcomes like spontaneous abortion, dead birth, or congenital anomalies (9). However, although there is a safe and influential influenza vaccination for mothers and babies born alive or when they are in mother's womb, the vaccination rates are disappointing in pregnant women (10). It is already known that the reason of not having vaccination among pregnant women often includes safety concerns, lack of awareness, and limited risk perception for themselves and for their babies in many countries including Turkey (11). Studies showed that women with more knowledge on the benefits of vaccination are more willing to receive vaccination during pregnancy (12).

In a study that was conducted in Saudi Arabia, the rate of seasonal influenza vaccination was $19.8 \%$ in pregnant women (13). However, in a similar study that was conducted in Italy, seasonal vaccination rate was reported as $9.7 \%$ (14); two studies conducted in the USA reported two different results as 64\% (15) and 4\% (16). The fact that there are different rates among countries shows that a global positive trend has not yet been created.

The purpose of this study was to evaluate the knowledge, attitudes and behaviour of pregnant women on seasonal influenza and vaccination for influenza.

\section{MATERIALS AND METHODS}

In this cross-sectional study, 268 adult pregnant women who were in the first, second and third trimester and who applied to the second clinic of the Bayburt Government Hospital, Bayburt, Turkey, between October 2018 and March 2019 were included. Informed consent forms were received from all patients. The pregnant women who did not want to participate in the study, and those who were under 18 years of age were excluded from the study, a total of 250 patients were included. The study was prepared in the prospective fashion, and approval was received from the Ethics Committee of Hamidiye Etfal Training and Research Hospital of the Health Sciences University (Ethics Committee Number: 2018/2138). A questionnaire that consisted of 5 sections was prepared by the authors of the study to apply to the patients by examining the relevant literature. Prior to the interviews, the participants were informed about the study and the privacy of the interview.

In the first part of the questionnaire, the socio-demographic characteristics of the pregnant women (age, educational status, occupation, pregnancy history, current gestational week, concomitant diseases and monthly net income levels) were questioned; and in the second part, history of having vaccination for influenza in current and previous pregnancies was questioned. The answers were given as "yes" and "no". In the third chapter, the perspectives of the participants on vaccination for influenza in pregnancy (concerns about the vaccination, benefits of the vaccination, safety of it, having or not having vaccination) were questioned. The answers were given as "yes" and "no". Options for interpretation were given for "yes" and "no" answers; the patients were told that they could select more than one option. In the fourth chapter, the knowledge of the participants on influenza and vaccination for influenza ("Is vaccination for influenza safe? In which trimester is it applied?") was questioned; the answers were received as "yes", "no" and "I do not know". In the fifth section, it was questioned whether information was given to them on influenza and vaccination for influenza during pregnancy; the answers were received as "yes" and "no".

The data were analyzed with the SPSS 20.0 Program (Statistical Package for the Social Sciences Inc.; Chicago, IL, the USA). Statistical evaluation was made as mean \pm standard deviation (mean $\pm \mathrm{SD}$ ), and as percentile values.

\section{RESULTS}

All the pregnant women who applied to the clinic between October 2018 and March 2019 were included in the study. Out of 268 participants, 11 women were not able to understand and speak Turkish language well due to their recent immigration. In addition, the participants who had adolescent pregnancy $(n=4)$ and those who did not fill their questionnaires adequately $(n=3)$ were excluded (total 18 pregnant women). A total of 250 participants were included in the statistical analysis.

The socio-demographic data of the participants are listed in Table 1. Table 2 shows the vaccination for influenza in this pregnancy and in the prior pregnancy and whether the vaccination was recommended by anyone. It was determined that $98 \%(n=245)$ of the participants stated that they were not vaccinated before; and $98.8 \%(n=247)$ did not have this vaccination in current pregnancy. In addition, it was also determined that $98.4 \%$ of the participants $(n=246)$ were not recommended by any health centre.

Table 3 shows the attitudes and viewpoints of the pregnant women on vaccination for influenza; $9.2 \%$ of the participants $(n=23)$ had no idea of the vaccination for influenza during pregnancy, while $5.2 \%(n=13)$ knew that pregnant women were in the risk group. Among the participants, only 1 patient $(0.4 \%)$ stated that she wanted to have vaccination for influenza because it was recommended by her doctor, 64 patients $(25.6 \%)$ did not want to have vaccination because their doctors were against the vaccination.

In Table 4 the knowledge level of the participants on influenza and vaccination for influenza is listed. 114 patients (45.6\%) knew that influenza was more dangerous during pregnancy, 92 (36.8\%) knew that vaccination was protective in pregnant women, 42 $(16.8 \%)$ patients thought that the vaccination was not protective, and $116(46.4 \%)$ patients stated that they did not have any ideas. There were 50 patients $(20 \%)$ who knew that the vaccination was safe, and 163 patients $(65.2 \%)$ had no idea.

The level of being informed on influenza and vaccination for influenza in pregnant women is listed in Table 5. It was determined that 232 patients $(92.8 \%)$ were not informed on vaccination for seasonal influenza for influenza.

\section{DISCUSSION}

In this cross-sectional descriptive study, it was determined that most of the patients did not have the knowledge that seasonal flu vaccination is safe during pregnancy and that it should be 
Table 1. Demographic data of pregnant women $(N=250)$

\begin{tabular}{|c|c|c|c|c|c|}
\hline & & Mean \pm SD & Std. error & Median (IQR) & Min-max \\
\hline \multicolumn{2}{|l|}{ Age } & $28.85 \pm 5.42$ & 0.34 & $28.5(8)$ & $18-43$ \\
\hline \multicolumn{2}{|l|}{ Gravida } & $2.16 \pm 1.28$ & 0.08 & $2(2)$ & $1-7$ \\
\hline \multicolumn{2}{|l|}{ Parity } & $0.89 \pm 0.91$ & 0.06 & $1(1)$ & $0-4$ \\
\hline \multicolumn{2}{|l|}{ Gestational week } & $19.00 \pm 9.75$ & 0.62 & $18(18)$ & $4-39$ \\
\hline & & & $\mathrm{n}(\%)$ & & \\
\hline \multirow{6}{*}{ Education } & \multicolumn{2}{|l|}{ None } & $4(1.6)$ & & \\
\hline & \multicolumn{2}{|l|}{ Primary } & $41(16.4)$ & & \\
\hline & \multicolumn{2}{|l|}{ Middle } & $40(16.0)$ & & \\
\hline & \multicolumn{2}{|l|}{ High } & $65(26.0)$ & & \\
\hline & \multicolumn{2}{|l|}{ University } & $86(34.4)$ & & \\
\hline & \multicolumn{2}{|l|}{ Master's degree } & $14(5.6)$ & & \\
\hline \multirow{5}{*}{ Profession } & \multicolumn{2}{|l|}{ Housewife } & $148(59.2)$ & & \\
\hline & \multicolumn{2}{|l|}{ Unemployed } & $9(3.6)$ & & \\
\hline & \multicolumn{2}{|l|}{ Worker } & $14(5.6)$ & & \\
\hline & \multicolumn{2}{|l|}{ Teacher } & $25(10.0)$ & & \\
\hline & \multicolumn{2}{|l|}{ Other } & $54(10.8)$ & & \\
\hline \multirow{3}{*}{ Income } & \multicolumn{2}{|l|}{ Subsistence wage } & $73(29.2)$ & & \\
\hline & \multicolumn{2}{|l|}{ Middle } & $106(42.4)$ & & \\
\hline & \multicolumn{2}{|l|}{ High } & $71(28.4)$ & & \\
\hline
\end{tabular}

recommended to every pregnant woman. It was determined that $98.8 \%$ of the pregnant women did not have vaccination in their pregnancy, and $65.2 \%$ did not know that the vaccination was safe. Again, it was determined that only $1.6 \%$ of the participants were informed on vaccination by healthcare staff.

In Turkey, the vaccination rates are far behind the rate that is recommended by the US Centers for Disease Control and Prevention (CDC) (90\%) (17). The rate of vaccination was found to be $1.2 \%$ in this study, which is far below the world average. In a study in which 12,235 cases were included in Turkey in 2006, the vaccination rate was found to be $4.5 \%$ (18).

In a similar study that was conducted in India, none of the pregnant women knew that seasonal influenza vaccination should be given to pregnant women (19). Similarly, in another study that was conducted in the US, $51 \%$ of the patients said that seasonal influenza was more dangerous in pregnant women, and $54 \%$ of the patients said that they knew that the seasonal influenza vaccination was safe (20). In our study, $45.6 \%$ of the pregnant women

Table 2. History of vaccination for influenza in current and previous pregnancies $(N=250)$

\begin{tabular}{|l|c|c|}
\hline \multicolumn{2}{|c|}{} & $\mathbf{n}(\%)$ \\
\hline Have you been vaccinated during your previ- & Yes & $5(2.0)$ \\
\cline { 2 - 3 } ous pregnancy? & No & $245(98.0)$ \\
\hline Did you get vaccinated during your current & Yes & $3(1.2)$ \\
\cline { 2 - 3 } pregnancy? & No & $247(98.8)$ \\
\hline Did your primary healthcare provider (doctor & Yes & $4(1.6)$ \\
\cline { 2 - 3 } $\begin{array}{l}\text { or nurse) recommend getting vaccinated for } \\
\text { influenza during your pregnancy? }\end{array}$ & No & $246(98.4)$ \\
\hline
\end{tabular}

said they knew that seasonal influenza was more dangerous in pregnancy, and $20 \%$ of the participants said that they knew that influenza vaccination was safe in pregnancy. When compared with the data reported in the literature, these rates are much lower at a significant level than the rates in the literature and the recommended rates.

The WHO reported that pandemic influenza (H1N1) infections were responsible for 18,449 deaths worldwide until May 23, 2010; and $4-13 \%$ of these deaths were pregnant women (21). Çelikel et al. conducted a study in Turkey in 2013 with 198 patients, the rate of having seasonal vaccination for influenza by pregnant women was found to be $3 \%$. This rate was also under the expected value, which is also the case in our study (22).

The most important reason for the low rates of vaccination in studies conducted in Turkey may be the insecurity about vaccination in general. The insecurity against vaccines is not only in Turkey but also all over the world. In previous studies, it was shown that most measles cases in the United States in the last 20 years were reported in 2014, and most of these cases were due to not agreeing to have the vaccination because of insecurity against it (23). According to the 2017 data released by the European Centre for Disease Protection and Prevention (ECDC), the number of measles cases was approximately three times higher than in 2016 in Europe, it was determined that $87 \%$ of the diagnosed cases refused to be vaccinated. And as a conclusion, 35 patients died because of measles epidemic in Europe (24).

This attitude towards vaccination decreased the rate of immunization at a worldwide scale. In Italy, the rate of vaccination against measles decreased to 85\%, and to 88\% in Europe in 2015 (25). In 2017 data, on the other hand, the frequency of diphtheria, tetanus and pertussis vaccination decreased to $92 \%$ in Europe, and to $91 \%$ in the USA (26). 
Table 3. Opinions on vaccination for influenza $(N=250)$

\begin{tabular}{|l|c|l|l|}
\hline \multicolumn{2}{|l|}{ Would you like to get vaccinated for influenza and why?* } & & $\mathrm{n}(\%)$ \\
\hline I have no idea & $\mathrm{n}(\%)$ & & \\
\hline No, I do not have risk for it & $23(9.2)$ & & $13(5.2)$ \\
\hline No, it can be harmful for my health & $45(18.0)$ & Yes, I belong to the risk group & $7(2.8)$ \\
\hline No, it can be harmful to the health of my baby & $37(14.8)$ & Yes, it is not harmful to my health & $10(4.0)$ \\
\hline No, it does not have any benefit & $60(24.0)$ & Yes, it is not harmful to the health of my baby & $10(4.0)$ \\
\hline No, my doctor was against & $42(16.8)$ & Yes, it is advantageous & $1(0.4)$ \\
\hline No, other & $64(25.6)$ & Yes, my doctor particularly recommended & $0(0.0)$ \\
\hline
\end{tabular}

${ }^{*}$ More than one response was chosen.

The reason why the rates of seasonal vaccination for influenza are low during pregnancy in Turkey may be that seasonal influenza vaccination is not included in the vaccination calendar that is prepared by the Ministry of Health. Although some countries, like our country, the UK, and Germany do not recommend influenza vaccination routinely (27), countries like the USA and Canada recommend the seasonal influenza vaccination to all pregnant women without considering the trimester (28). In a study that was conducted in Australia, the vaccination for influenza was $31 \%$ in pregnant women in the second and third trimester; the seasonal vaccination for influenza was determined to be $31 \%$ in pregnant women (29). As it is seen, the time of recommending seasonal influenza vaccination and being in the routine schedule vary from country to country.

Table 4. Knowledge level on influenza and vaccination for influenza $(N=250)$

\begin{tabular}{|l|l|c|c|}
\hline \multirow{2}{|l|}{} & $\mathbf{n}$ & $\%$ \\
\hline \multirow{3}{*}{$\begin{array}{l}\text { Influenza is more dangerous } \\
\text { during pregnancy }\end{array}$} & Yes & 114 & 45.6 \\
\cline { 2 - 4 } & No & 29 & 11.6 \\
\cline { 2 - 4 } & I do not know & 107 & 42.8 \\
\hline \multirow{3}{*}{$\begin{array}{l}\text { Vaccination can protect preg- } \\
\text { nant women against influenza }\end{array}$} & Yes & 92 & 36.8 \\
\cline { 2 - 4 } & No & 42 & 16.8 \\
\cline { 2 - 4 } & I do not know & 116 & 46.4 \\
\hline \multirow{3}{*}{$\begin{array}{l}\text { Influenza vaccination is recom- } \\
\text { mended for pregnant women }\end{array}$} & Yes & 37 & 14.8 \\
\cline { 2 - 4 } & No & 53 & 21.2 \\
\cline { 2 - 4 } & I do not know & 160 & 64.0 \\
\hline \multirow{3}{*}{$\begin{array}{l}\text { It is recommended during the } \\
\text { first trimester }\end{array}$} & Yes & 14 & 5.6 \\
\cline { 2 - 4 } & No & 45 & 18.0 \\
\cline { 2 - 4 } & I do not know & 191 & 76.4 \\
\hline \multirow{3}{*}{$\begin{array}{l}\text { It is recommended during the } \\
\text { second trimester }\end{array}$} & Yes & 17 & 6.8 \\
\cline { 2 - 4 } & No & 30 & 12.0 \\
\cline { 2 - 4 } & I do not know & 203 & 81.2 \\
\hline \multirow{3}{*}{$\begin{array}{l}\text { It is recommended during the } \\
\text { third trimester }\end{array}$} & Yes & 11 & 4.4 \\
\cline { 2 - 4 } & No & 33 & 13.2 \\
\hline \multirow{3}{*}{$\begin{array}{l}\text { Influenza vaccination is safe } \\
\text { during pregnancy }\end{array}$} & I do not know & 206 & 82.4 \\
\hline & Yes & 50 & 20.0 \\
\cline { 2 - 4 } & No & 37 & 14.8 \\
\hline \multirow{2}{*}{ I do not know } & 163 & 65.2 \\
\hline
\end{tabular}

In some publications, it was reported that rates of seasonal vaccination for influenza in pregnant women may be low because of the fact that the time of the study was outside the influenza season (22).

In a study conducted in Italy, it was determined that the vaccination rates in women with secondary education level were lower than in women with university degrees (14). In addition, again in the same study, it was reported that as the number of pregnancies increased, the number of vaccinations decreased. Contrary to this study, however, in our study, despite the fact that the majority of the participants consisted of university graduates, the awareness on the vaccination was low. Nevertheless, unlike the abovementioned study, we did not evaluate the number of pregnancies in our study.

In Turkey, one of the biggest incorrect approaches is the confusion of influenza and common cold, and people believing that they can overcome the seasonal influenza easily. This causes that they do not need to have the influenza vaccination (30). When the contribution of the vaccination to the economy of the country is

Table 5. Providing information on influenza and vaccination for influenza in pregnancy $(N=250)$

\begin{tabular}{|c|c|c|}
\hline & & $\mathrm{n}(\%)$ \\
\hline \multirow{6}{*}{$\begin{array}{l}\text { Were you informed about influenza } \\
\text { during your pregnancy? }\end{array}$} & No & $230(92)$ \\
\hline & Yes, doctor/nurse & $11(4.4)$ \\
\hline & Yes, media & $9(3.6)$ \\
\hline & Yes, friend & $0(0.0)$ \\
\hline & Yes, family & $0(0.0)$ \\
\hline & Other & $0(0.0)$ \\
\hline \multirow{6}{*}{$\begin{array}{l}\text { Were you informed about vac- } \\
\text { cination for influenza during your } \\
\text { pregnancy? }\end{array}$} & No & 232 (92.8) \\
\hline & Yes, doctor/nurse & $10(4.0)$ \\
\hline & Yes, media & $5(2.0)$ \\
\hline & Yes, friend & $2(0.8)$ \\
\hline & Yes, family & $1(0.4)$ \\
\hline & Other & $0(0.0)$ \\
\hline \multirow{2}{*}{$\begin{array}{l}\text { Do you think that you need more } \\
\text { information about influenza during } \\
\text { pregnancy? }\end{array}$} & Yes & $134(53.6)$ \\
\hline & No & $116(46.4)$ \\
\hline \multirow{2}{*}{$\begin{array}{l}\text { Do you think that you need more } \\
\text { information about vaccination for } \\
\text { influenza during pregnancy? }\end{array}$} & Yes & 139 (55.6) \\
\hline & No & $111(44.4)$ \\
\hline
\end{tabular}


considered, it is seen that seasonal influenza vaccination provided noticeable savings in terms of costs (31). The long-term contribution to the national economy must be considered when the cost of hospital applications made by seasonal influenza, medical costs, loss of labour costs, and efficiency and costs through vaccination are compared.

Another reason for low vaccination rates was the fact that the vaccination against seasonal influenza was not recommended by doctors or healthcare professionals $(19,32)$.

In a multicentre study conducted by Broughton et al., the attitudes and behaviours of healthcare employees who worked in obstetrics centres on vaccination for influenza during pregnancy were evaluated. It was determined in the study that approximately one third of the healthcare employees working in these healthcare centres did not believe that vaccination was a safe and effective way to reduce infections (31\%), and only $36 \%$ knew that vaccination was safe in pregnancy. Again, in the same study, it was emphasized that the lack of knowledge on vaccination for influenza during pregnancy among healthcare employees was alarming (33).

In a study conducted in Canada by Tong et al., the knowledge, attitudes and behaviours of the gynaecologists and pregnant women on the vaccination for influenza were examined, and the reasons for not accepting the vaccination by pregnant women were investigated (34). In the same study, the rate of seasonal vaccination for influenza during pregnancy was determined as $6.7 \%$, and it was reported that this rate was low. In addition, the rate of vaccination was higher in women who had high knowledge on maternal vaccination. Similarly, it was also found that the vaccination rates were high in pregnant women who were recommended for vaccination by healthcare centres. In a study conducted in 6 European countries (Bulgaria, Czech Republic, Kosovo, Poland, Romania, and United Kingdom) in 2018, the effects of healthcare employees on the acceptance and advocacy of the influenza vaccination was investigated. It was reported in this study that the main cluster (i.e. the confident sentiment was $73 \%$ ) showed strong positive attitudes regarding vaccination advocacy, and the second cluster (i.e. diffident sentiment was $27 \%$ ) showed neutral attitudes (35). In Turkey, consistent with the literature data, it was determined that the rates of patients who received vaccination advice by healthcare employees were low.

In the literature, the most common cause for low vaccinations rates is that pregnant women think that vaccination is not safe $(25,26)$. In our study, $65.2 \%$ of the patients stated that they did not have any information about the safety of the vaccination, and $14.8 \%$ said that vaccination was not reliable, which is quite inadequate as the rates reported in the literature. When all the reasons are considered in this respect, we think that the role of doctors is important. When doctors recommend the patients about the effectiveness, reliability and necessity of the seasonal influenza vaccination, it may increase the rates positively by providing the patients with adequate information.

In Turkey, among the reasons of the low rates of suggestion of seasonal influenza vaccination by doctors, we believe that doctors have an intensive working tempo, lack of knowledge on vaccinations, reservations of doctors about vaccination, and the fact that seasonal influenza vaccination is not included in the routine vaccination calendar of the Ministry of Health.

There are some limitations in this study. Firstly, a standardized and accepted questionnaire was not employed in the present study, however, our data collection form was not designed to measure the severity of a medical condition or to evaluate the response to treatment; for this reason, we believe that this is not a limiting factor. Secondly, as the study was a single-centre study, it is not possible to make a general evaluation with the current results. Thirdly, while the data were analyzed, no sub-group proportional analyses were made with the educational status and pregnancy counts.

\section{CONCLUSION}

As a conclusion, the vaccination rates of the pregnant women who participated in this study were very low. It is considered that the main reason for this situation was the misconceptions and information deficiencies of the pregnant women on influenza and vaccination for influenza. The seasonal vaccination for influenza rates were found to be very low in current and prior pregnancies of the pregnant women. The main reason for this is the inaccurate and incomplete information given by healthcare employees on seasonal vaccination for influenza.

\section{Authors' Contribution}

ÇP - study conception and design, analysis and interpretation of data, acquisition of data, manuscript writing; GT - acquisition of data, critical revision, editing of manuscript.

\section{Conflict of Interests}

None declared

\section{REFERENCES}

1. Iuliano AD, Roguski KM, Chang HH, Muscatello DJ, Palekar R, Tempia $\mathrm{S}$, et al. Estimates of global seasonal influenza-associated respiratory mortality: a modelling study. Lancet. 2018;391(10127):1285-300.

2. Fell DB, Azziz-Baumgartner E, Baker MG, Batra M, Beauté J, Beutels $P$, et al. Influenza epidemiology and immunization during pregnancy: final report of a World Health Organization working group. Vaccine. 2017;35(43):5738-50.

3. Fiore AE, Shay DK, Broder K, Iskander JK, Uyeki TM, Mootrey G, et al. Prevention and control of influenza: recommendations of the Advisory Committee on Immunization Practices (ACIP), 2008. MMWR Recomm Rep. 2008;57(RR-7):1-60.

4. Global Advisory Committee on Vaccine Safety. Safety of immunization during pregnancy. A review of the evidence. Geneva: WHO; 2014.

5. T. C. Official newspaper. Social Security Institution. Notification of changes in health practice. Official gazette dated 26 November 2016 and numbered 29900 [Internet]. [cited 2020 May 3]. Available from: https:// www.resmigazete.gov.tr/eskiler/2016/11/20161126-13.htm. (In Turkish.)

6. Dodds L, McNeil SA, Fell DB, Allen VM, Coombs A, Scott J, et al. Impact of influenza exposure on rates of hospital admissions and physician visits because of respiratory illness among pregnant women. CMAJ. 2007;176(4):463-8

7. Tamma PD, Steinhoff MC, Omer SB. Influenza infection and vaccination in pregnant women. Expert Rev Respir Med. 2010;4(3):321-8.

8. Thompson MG, Kwong JC, Regan AK, Katz MA, Drews SJ, AzzizBaumgartner $\mathrm{E}$, et al. Influenza vaccine effectiveness in preventing influenza-associated hospitalizations during pregnancy: A multi-country retrospective test negative design study, 2010-2016. Clin Infect Dis. 2019;68(9):1444-53.

9. Fell DB, Platt RW, Lanes A, Wilson K, Kaufman JS, Basso O, et al. Fetal death and preterm birth associated with maternal influenza vaccination: Systematic review. BJOG. 2015;122(1):17-26.

10. Mereckiene J. Seasonal influenza vaccination in Europe. Overview of vaccination recommendations and coverage rates in the EU Member States for the 2012-13 influenza season. Stockholm: ECDC; 2015. 
11. Freund R, Le Ray C, Charlier C, Avenell C, Truster V, Tréluyer JM, et al. Determinants of non-vaccination against pandemic $2009 \mathrm{H} 1 \mathrm{~N} 1$ influenza in pregnant women: A prospective cohort study. PLoS One. 2011;6(6):e20900. doi: 10.1371/journal.pone.0020900.

12. Fabry P, Gagneur A, Pasquier JC. Determinants of A(H1N1) vaccination: Cross-sectional study in a population of pregnant women in Quebec. Vaccine. 2011;29(9):1824-9.

13. AlMusailhi SA, AlShehri NM, AlHarbi WM. Knowledge, utilization and barriers of pregnant women to influenza vaccine in primary health care centers in Dammam and Al Khobar, Saudi Arabia, 2017-2018. Int J Womens Health. 2019;11:207-11.

14. Napolitano F, Napolitano P, Angelillo IF. Seasonal influenza vaccination in pregnant women: Knowledge, attitudes, and behaviors in Italy. BMC Infect Dis. 2017;17(1):48. doi: 10.1186/s12879-016-2138-2.

15. Fisher BM, Scott J, Hart J, Winn VD, Gibbs RS, Lynch AM, et al. Behaviors and perceptions regarding seasonal and H1N1 influenza vaccination during pregnancy. Am J Obstet Gynecol. 2011;204(6 Suppl 1):107-11.

16. Ding H, Black CL, Ball S, Fink RV, Williams WW, Fiebelkorn AP, et al. Influenza vaccination coverage among pregnant women - United States, 2016-17 influenza season. MMWR Morb Mortal Wkly Rep. 2017;66(38):1016-22.

17. Office of Disease Prevention and Health Promotion. Healthy People 2020 [Internet]. Washington: U.S. Department of Health and Human Services; 2015 [cited 2015 Aug 20]. Available from: http://www.healthypeople. gov/2020/topics-objectives/topic/immunization-and-infectiousdiseases/ objectives.

18. Özışık L, Başaran NÇ, Ünal S. Every aspect of influenza 2016: Turkey. İç Hastalıkları Dergisi. 2016;23(1):1-11. (In Turkish.)

19. Koul PA, Bali NK, Ali S, Ahmad SJ, Bhat MA, Mir H, et al. Poor uptake of influenza vaccination in pregnancy in northern India. Int J Gynaecol Obstet. 2014;127(3):234-7.

20. Eppes C, Wu A, You W, Cameron KA, Garcia P, Grobman W. Barriers to influenza vaccination among pregnant women. Vaccine. 2013;31(27):2874-8.

21. Blanchard-Rohner G, Siegrist CA. Vaccination during pregnancy to protect infants against influenza: Why and why not? Vaccine. 2011;29(43):7542-50.

22. Celikel A, Ustunsoz A, Guvenc G. Determination of vaccination status of pregnant women during pregnancy and the affecting factors. J Clin Nurs. 2014;23(15-16):2142-50.

23. Centers for Disease Control and Prevention. Measles cases in the United States reach 20-year high [Internet]. U.S. Department of Health \& Human Services; 2014 [cited 2018 Feb 2]. Available from: https://www.cdc.gov/ media/releases/2014/ p0529-measles.html.
24. European Centre for Disease Prevention and Control. Measles cases in the EU treble in 2017, outbreaks still ongoing [Internet]. Solna: ECDC; 2018 [cited 2018 Mar 2]. Available from: https://ecdc.europa.eu/en/ news-events/measles-cases-eutreble-2017-outbreaks-still-ongoing.

25. OECD Data. Child vaccination rates [Internet]. Paris: OECD [cited 2018 Feb 27]. Available from: data.oecd.org/healthcare/child-vaccination-rates. htm.

26. WHO. Global and regional immunization profile: European Region [Internet]. 2017 [cited 2018 Feb 28]. Available from: http://www.who. int/immunization/monitoring surveillance/data/gs eurprofile.pdf ?ua=1.

27. Turkish Republic Ministry of Health, General Directorate of Primary Health Care. Pandemic A (H1N1) vaccination report [Internet]. Ankara: Turkish Republic Ministry of Health; 2009 [cited 2020 May 3]. Available from: ibtf.ibu.edu.tr/eskisite/duyuru/panh1.pdf.

28. Mak TK, Mangtani P, Leese J, Watson JM, Pfeifer D. Influenza vaccination in pregnancy: current evidence and selected national policies. Lancet Infect Dis. 2008;8(1):44-52.

29. Lu AB, Halim AA, Dendle C, Kotsanas D, Giles ML, Wallace EM, et al. Influenza vaccination uptake amongst pregnant women and maternal care providers is suboptimal. Vaccine. 2012;30(27):4055-9.

30. Gündüz S, Yüksel ÇN, Aktoprak HB, Canbal M, Kaya M. Attitudes towards influenza vaccination in high socioeconomic status Turkish parents. Turk J Med Sci. 2014;44(4):649-55.

31. Peasah SK, Azziz-Baumgartner E, Breese J, Meltzer MI, Widdowson MA. Influenza cost and cost-effectiveness studies globally - A review. Vaccine. 2013;31(46):5339-48.

32. Yuen CYS, Dodgson JE, Tarrant M. Perceptions of Hong Kong Chinese women toward influenza vaccination during pregnancy. Vaccine. 2016;34(1):33-40.

33. Broughton DE, Beigi RH, Switzer GE, Raker CA, Anderson BL. Obstetric health care workers' attitudes and beliefs regarding influenza vaccination in pregnancy. Obstet Gynecol. 2009;114(5):981-7.

34. Tong A, Biringer A, Ofner-Agostini M, Upshur R, McGeer A. A crosssectional study of maternity care providers' and women's knowledge, attitudes, and behaviours towards influenza vaccination during pregnancy. J Obstet Gynaecol Can. 2008;30(5):404-10.

35. Kassianos G, Kuchar E, Nitsch-Osuch A, Kyncl J, Galev A, Humolli I, et al. Motors of influenza vaccination uptake and vaccination advocacy in healthcare workers: A comparative study in six European countries. Vaccine. 2018;36(44):6546-52.

Received May 8, 2019

Accepted in revised form May 3, 2020 